\title{
Shipping digitalization management: conceptualization, typology and antecedents
}

\author{
Maria Lambrou ${ }^{1 *}$ (D), Daisuke Watanabe ${ }^{2}$ and Junya lida ${ }^{3}$
}

\author{
* Correspondence: mlambrou@ \\ aegean.gr \\ ${ }^{1}$ University of the Aegean, \\ Department of Shipping, Trade and \\ Transport, Chios, Greece \\ Full list of author information is \\ available at the end of the article
}

\begin{abstract}
Digital transformation is a topical theme in shipping research and professional practice, today. Our paper aims at developing a comprehensive framework of digitalization technologies and their maritime business implications, grounded on available evidence. In order to understand the full complexity of shipping digitalization activities, we addressed technology and management aspects in a coalesced framework. Our research follows a qualitative, case study approach. Five cases of advanced, shipping incumbents' digitalization activities were investigated. Our research outcome is an overarching theoretical model, which systematizes the technological components (technology typology), the prevailing management rationales (strategic drivers) and determinant factors (practices) of shipping digitalization.
\end{abstract}

Keywords: Shipping digitalization, Internet of things, Artificial intelligence, Blockchain, Digitalization management, Innovation

\section{Introduction}

Digitalization is already transforming shipping companies' operations and strategies. Primarily, shipping digitalization generates novel business logics and new business models for economic and social value creation (Andal-Ancion et al., 2012; Colbert et al., 2016; Chesbrough, 2010; Fitzgerald et al., 2014; Osterwalder, et al., 2005). As commonly acknowledged, however, further research is needed in order to frame the complexities of shipping digitalization, in a scholarly manner, and henceforth identify management approaches of rigor and practical significance to modern day shipping activities. Extant research offers an important knowledge base, in view of various types of information technology applications used in shipping, trade and transport. A broad range of decision support systems for shipping operational optimization (El Noshokaty, 2017), information systems for port logistics support (Mlimbila and Mbamba, 2018), and tools for policy-makers (Szimba et al., 2018) constitute the legacy of contemporary shipping digitalization. Our study addresses the following primary research questions: which are the effectual technologies of contemporary shipping digitalization and how these technologies resonate in shipping management; which management logics necessitate the adoption of digital technologies in shipping and which digitalization management practices enable them.

(c) The Author(s). 2019 Open Access This article is distributed under the terms of the Creative Commons Attribution 4.0 International License (http://creativecommons.org/licenses/by/4.0/), which permits unrestricted use, distribution, and reproduction in any medium, provided you give appropriate credit to the original author(s) and the source, provide a link to the Creative Commons license, and indicate if changes were made. 
Our research motivation is to develop a deeper understanding of digitalization technologies and their maritime business implications, grounded on available evidence. In order to understand the full complexity of related digitalization activities and incumbents' adaptation and revitalization efforts, we addressed technology and management aspects in a coalesced framework. Furthermore, we conducted a multi-case study to test and extend our theory, in view of how incumbent organizations in the shipping sector manage digitalization, related with an array of technologies, namely IoT, data analytics, artificial intelligence and blockchain.

Our multi-case, qualitative research took place within five of the largest and most advanced shipping institutions, worldwide; including two shipping companies, one classification society and one autonomous ship and one maritime blockchain consortium, henceforth making the research setting suitable for investigating the phenomenon of interest, namely shipping digitalization - constituent technologies and management dimensions and determinants.

With our paper, we propose an overarching theoretical model, which systematizes the technological components, the prevailing management rationales and determinant factors of digitalization.

Our paper is structured as follows: In section 2, we elaborate a baseline model of shipping digitalization that embeds three intertwined pillars: (i) digital technologies (IoT, big data analytics, A.I., blockchain), (ii) digital solutions (smart shipping systems and novel digital services), and (iii) digital business concepts, models and practices (digitalization strategic drivers, capabilities and innovation process). In section 3, we elaborate the typology of shipping technologies and solutions identified, while in section 4, the digitalization management aspects are presented in detail. The research process and findings are outlined throughout sections 2 and 4, as well as in section 5, where our field study cases are outlined. In section 6, we summarize our theoretical contribution, our research limitations as well as the managerial implications. Finally, future research is discussed in section 7 .

\section{Conceptualization of shipping digitalization}

\section{The research process}

Our research process encompassed the research gap identification, the theoretical model formulation, the case study design, and data collection, the framework validation and furthermore iterative theory elaboration, as emerged from and anchored in our field research data. In that sense, our study design was determined by our academic and professional experiences, predispositions and perceptions about shipping digitalization, but also allowed for the emergence of new theoretical insights (Legner et al., 2017; Saldana, 2009).

For our literature review (which informed our research gap identification and the proposed framework formulation), we conducted an exhaustive search of related publications during the last 3 years, in the Association of Information Systems (AIS) "basket" of journals and conferences which are identified as the leading sources in IS research. Likewise, we have based our theoretical framework development on related searches in Academy of Management (AOM) journals and conferences, primary sources in

Management Science and Innovation Management, henceforth having acquired a 
representative overview of the research streams, themes and issues in both these academic communities. More in specific, six main research streams for shipping digitalization management were considered most pertinent, namely digital strategy, digital innovation, Industry 4.0, and adjacently the themes of business models, analytics and blockchain. Having exhaustively searched the above sources, with respective keywords, in a subsequent search iteration, we have identified a number of finer grained research perspectives of interest, which can articulate the idiosyncrasies of shipping digitalization management logics and factors of implementation and management, presented in the following sections.

Our research is complemented with a continuous, longitudinally performed scanning of related, evolving literatures in Information Systems and Software Technology, also Maritime Studies; furthermore publications in non-academic press related with digital market, ship and port technologies, have been considered. We reviewed various studies from consulting companies (e.g., Boston Consulting Group, EY, Accenture) and IT vendors (e.g., IBM, Kongsberg, Wärtsilä), which have enabled us to critically assess, contextualize, filter and synthesize the prevailing research perspectives for the purpose of our study.

Hence, we complemented theoretical insights from first tier academic literature with practical insights from sector specific analyses. Although the results of the later studies were generic or vendor specific, they offered a valuable complementary perspective of shipping business and market trends and orientations.

The theoretical framework outlined in the following has emerged during the field research process and two distinct rounds of theoretical development. Elements of the latest iteration of theory development are given in the concluding section. The main steps, approach, results and methods of our research process are depicted in Fig. 1.

\section{The model}

Our baseline conceptual model is based on the conceptual analysis proposed by Wiesböck (2018). Henceforth, digital innovation in shipping is articulated along three basic pillars: (1) innovative digital technologies (IoT, analytics, A.I., blockchain) (2) innovative digital solutions (smart shipping systems and services, maritime blockchains), and (3) digital business concepts, models and management practices (i.e. digital mindset and skillset, technology partnerships, digitalization resourcing).

Based on generic digital technologies, shipping companies and maritime organizations develop industry and company specific innovative digital solutions and integrate them in their existing (inter) organizational and technical systems. This process includes the sourcing, technical and organizational adaptation, as well as the management of digital infrastructures (assets) and technology applications. Accordingly, the transition from a generic digital technology, like IoT or big data analytics platform to a particular shipping digital solution, like a predictive maintenance solution, characterizes an organization's digitalization. Innovative digital solutions, in turn, shape and are being shaped by the emergence of innovative digital business concepts and practices that are intertwined with digital solutions. This transformation process embedded in digital solutions and enacted with digital business models and practices is defined as digital transformation and captures the organizational changes and business model 


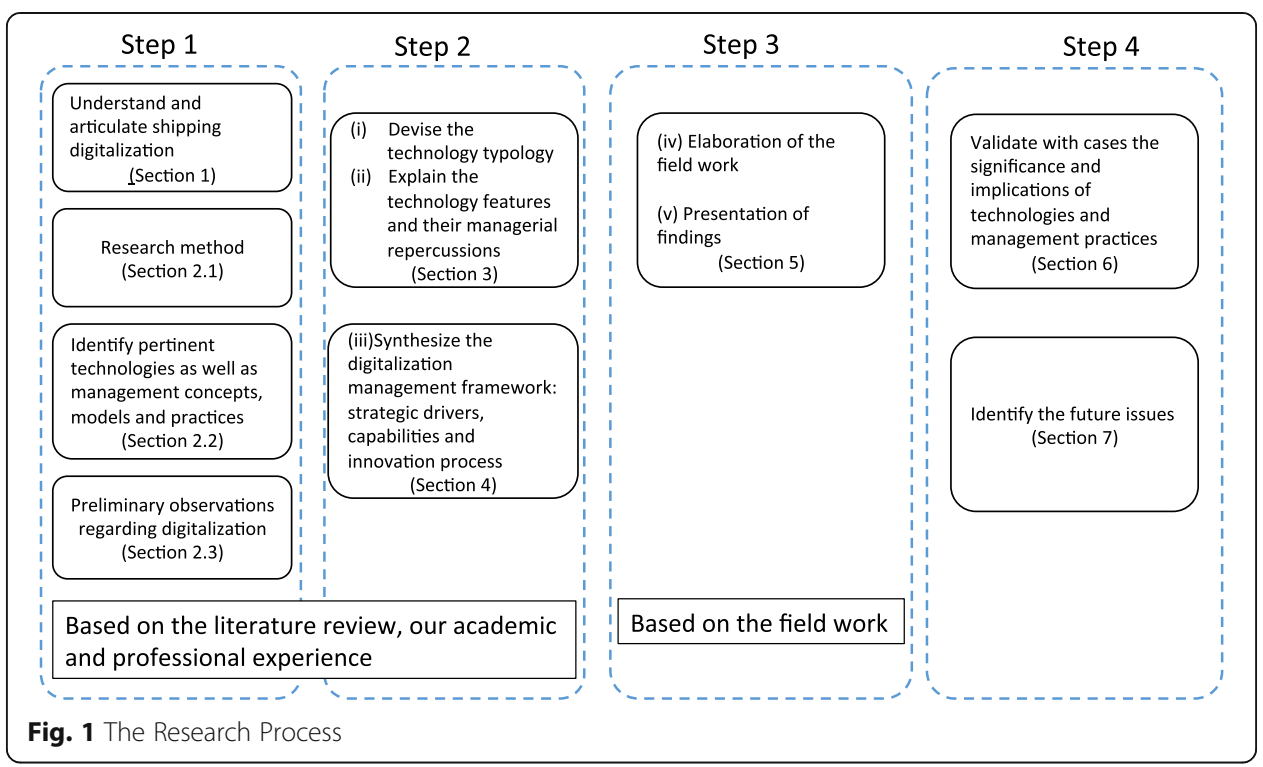

innovations induced by digital technologies (Atzori et al. 2010; Beck et al. 2017; Bharadwaj et al. 2013; Bordeleau et al. 2018; Demirkan et al. 2015; Kane et al. 2015). Our baseline conceptual model is illustrated in Fig. 2.

In the same line of thought, the implementation and management of innovative digital technologies represents the foundation of digital innovation (Nambisan et al. 2017) and is based on new configurations of physical and digital resources (Henfridsson and Bygstad 2013). The capability to (re)source and manage digital assets (i.e. order newbuildings with IoT hardware, communications networks) orchestrated along with conventional (analog) shipping companies' resources is central to shipping digitalization. In essence, a revised resource-based view and an enriched dynamic capabilities frame of sense making are most prevalent today.

According to the resource-based view of the firm, company-specific assets, resources and capabilities enable shipping companies to differentiate. Competitive advantage is

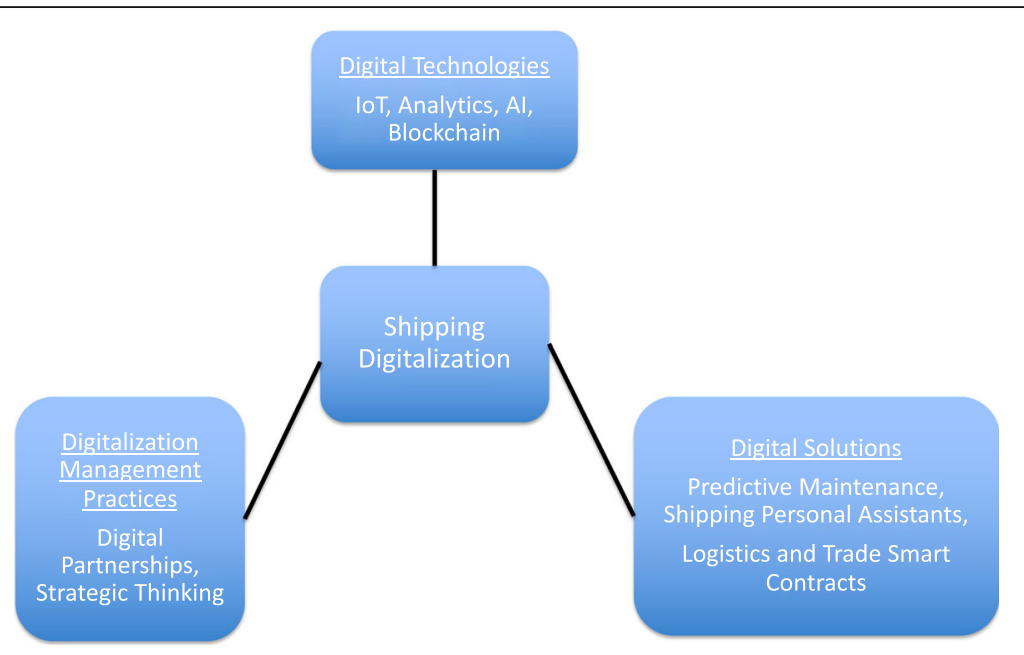

Fig. 2 A Baseline Model of Shipping Digitalization 
achieved while internal resources and capabilities are valuable, rare, inimitable and non-substitutable (Barney, 1991). Complementarily, a dynamic capabilities framework extends the resource-based viewpoint by emphasizing a (shipping) company's ability to "integrate, build, and reconfigure internal and external competences to address rapidly changing environments" (Teece, Pisano, and Shuen, 1997). This capacity is further identified as comprising the ability to "sense," "seize" and "transform" opportunities, often denoted as "orchestration" capabilities. Theory further extending this argument informs us that complex, tacit, historically shaped and hence idiosyncratic set of routines and competencies shall determine the digitalization outcomes of different shipping incumbents. Commonalities also exist across shipping companies in digitalization efforts (Eisenhardt and Martin 2000). Hence resources and capabilities are more homogeneous across firms than traditional resource-based logic postulates, exhibiting best practices.

Against this background, digitalization management literature, as hereafter also appropriated in the shipping context, habitually takes a rationalistic, positivist, and practice-oriented perspective on capabilities. In order to create and operate digital business models and management practices shipping companies need the develop and enact a digitalization capability, which may be reduced to a set of simple rules and process heuristics (best practices); an ability to think strategically about digital technologies, approaching digitalization as an opportunity for new value creation (Barrett et al., 2015). Leveraging digital assets as the primary strategic resources, steering the transformation of the core shipping operations and henceforth orchestrating both physical and digital shipping resources and activities is central to value creation and capture in shipping digitalization. Organizing and partaking in technology-based business relationships and digital innovation ecosystems are related digitalization antecedents (Lyytinen et al. 2016; Nambisan et al. 2017; Yoo et al. 2010).

\section{The observations}

Indeed, our preliminary observations regarding digitalization management practices reveal that incumbent, leading shipping companies, today, primarily develop innovative digital solutions (i.e. blockchain based smart contracts) while aligning strategic and operational needs and objectives with digital technologies affordances. Shipping strategy is hardly a pure, digital first strategy today; nonetheless digital technology affordances are ingrained in a multifold of heterogeneous strategic orientations of shipping companies today. Digital resources, such as modern cyber-physical assets, data assets and employees with digital skills, are acquired and orchestrated in various modes and fashions, in order to address the high uncertainty that intertwined, volatile shipping markets and high velocity digital markets entail.

In addition, shipping companies and maritime organizations actualize the necessary conditions with respective organization design choices, taking the form of appropriate structures, i.e. creating new digital business units or smart shipping departments, as well as with related governance mechanisms, i.e. cross departmental/organizational collaboration, forming digital technology partnerships, research consortia and joint ventures, which seemingly enable them to leverage digital technologies. 
Apparently, shipping companies with digitization engagements complement digital solutions with innovative digital business concepts, models and practices (Svahn et al., 2017).

In the following, we elaborate further the particular elements of our baseline model of shipping digitalization.

\section{Shipping digitalization: technologies and solutions}

We outline the technological underpinnings of shipping digitalization and present a concise typology of shipping technology affordances.

A multitude of orthogonal or intertwined technologies, such as A.I. algorithms and blockchain platforms, create a multitude of digital solutions, such as digital assistants for shipping professionals or secure, decentralized cargo-tracking processes (Table 1). Digital technologies and solutions for shipping are further intertwined with related supply chain technologies and solutions (Pfohl et al., 2015).

\section{Internet of ships and sea services}

IoT technology, namely sensors, actuators, or processors are embedded in vessels' technical systems, namely engines, communications and data fusion systems, propellers or cargo systems, constituting the Internet of Ships and Sea Services. (Levander, 2017) Embedded software platforms integrate and manage the increasingly automated functions of ships and the interconnected shipping business processes, as well as the connected maritime logistics service systems (Lycett, 2013; Shmueli et al., 2011; Thomas et al., 2014). Developments in 5G communications systems, satellite for 5G and converged fixed and mobile segments as well $5 \mathrm{G}$ edge nodes architectures is a major technological pillar of the Internet of Ships and Sea Services.

\section{Artificial intelligence: autonomous vessels and smart shipping}

Artificial Intelligence (A.I.) in shipping has two distinct application areas:

Firstly, the autonomous vessels technology, as materialized by applying various techniques and technologies ascribed in general as artificial intelligence. Machine learning techniques for improved situation awareness support a number of ship operations and functions, including anomaly detection for navigation, maneuvering or collision

Table 1 Shipping Digital Solutions

\begin{tabular}{ll}
\hline Digitalization Areas & Digital Technologies-Solutions \\
\hline Ship Operations-Autonomous Functions & IoT, analytics, Al, 5G \\
& Technical and nautical operations \\
& Various levels of Autonomy for Ship Operations: \\
& Navigation, Berthing, Collision Avoidance \\
Shipping Commercial and Business & loT, analytics, Al \\
Management Operations & Asset optimization, fleet planning, service planning \\
Trade and Logistics Functions & IOT, analytics, blockchain \\
Digital Platforms & Cargo monitoring, Paperless Trade, Supply Chains \\
& Synchronization \\
Internet of Ships Platforms \& & Analytics, Al \\
Internet of Sea Services Platforms & Smart Cargo Booking \\
& Open Data Hub for shipping companies, shipbuilders, \\
& equipment manufacturers, IT companies, weather \\
information companies, and digital solution providers.
\end{tabular}


avoidance. Condition based monitoring of ship mechanical systems (i.e. predictive maintenance) is another major application area.

Self-management and autonomous systems design principles and capabilities, i.e. monitoring, control, optimization and autonomy at various levels (0-5 or 6) and functional areas of ship operations (navigation, cargo handling) are relevant.

In general, an autonomous ship is operated by a land-based surveillance and control center connected with a collection of digital technologies such as IoT, data analysis technology, and broadband communication. Highly automated (autonomous) or remote controlled or remote control of certain tasks of shipboard operations like vessel operations, cargo management / cargo handling, are distinguished (Jokioinen, 2017).

Secondly, smart shipping is related with commercial and business operations optimization. A.I. is supporting a number of application areas at the tactical level of shipping management, including asset optimization, fleet planning, service planning and chartering. Energy consumption monitoring and environmental regulations compliance software are also smart shipping (digital solutions) instances.

Likewise, strategic level smart applications, such as shipping markets monitoring software and personal digital assistants. A broader spectrum of A.I. use cases transforming ship and shipping operations (i.e. planning, commercial operations and business operations), in diverse shipping sub-sectors is in the advent (Loebbecke et al. 2015; Lycett, 2013; McAfee and Brynjolfsson, 2012).

\section{Blockchains for maritime logistics and trade}

Blockchain technology, in particular, a number of proof of concept systems have already been developed and tested. Exemplar platforms, namely TradeLens, Insurwave and CargoX are in commercial operation. Maritime enterprise blockchains implement smart contracts over permissioned (private) blockchain platforms, and primarily digitise trade documentation processes. Fewer applications account to IoT enabled blockchains for cargo and ship machinery monitoring. A few prototyped applications also include shipping crypto currency services.

Hyperledger Fabric, Enterprise Ethereum and R3-Corda Enterprise platforms constitute the basic technology (infrastructure layer) used for the development, deployment and operation of maritime enterprise blockchains (application layer), and they evolve continuously. (Pilkington, 2016; Sternberg and Baruffaldi, 2018; Underwood, 2016).

Maritime blockchain applications also evolve continuously, towards materializing the transformational potential of blockchain technology, beyond incrementally improved paperless operations management, or distributed but not decentralized physical asset management. The business model of Distributed Autonomous Organizations, where shipping is algorithmically managed, coalescing the above technologies (IoT, 5G, A.I. and blockchain) into autonomous solutions may be tested soon too.

\section{Digitalization management: concepts, models and practices Digital strategy and business models}

Digital business strategy has longitudinally and consistently been articulated along the merely "tactical and operational" objectives of cost-reductions, process improvements or operational excellence, as well as the objectives of supplier and customer 
engagement, insight and decision support aims. The research streams of business models and digital innovation have enriched the discussion with new angles for value creation and digital value propositions as well as data monetization (Kane et al., 2015; Nylén and Holmstrom, 2015; Liere-Netheler, et al., 2018; Teece, 2010; Zott et al., 2011).

We employ a dual, theory-based and practice oriented approach to identify digital strategy and value creation logics in shipping.

The construct of drivers is used in order to address digital strategy (Liere-Netheler, et al., 2018). Drivers are understood as the perceived or expected business advantages that result from embedding digital technology in shipping operations, smart shipping systems or new business models, such as blockchain-enabled smart contracts and open, Internet of Ships platforms for data sharing and shipping services.

Furthermore, the notion of value creation and digital business models is used; in specific how the notion of value creation resonates and is operationalized in the context of digital strategy in shipping, how it is understood by practitioners and to what extend it is a utilitarian, practice oriented construct that enables the actualization of digitalization initiatives.

Remarkably, in our field study, shipping organizations interviewees consistently avoided to respond to value creation related questions and prompts, contrary to the questions and prompts addressing the drivers and strategies for digitalization that were regularly, eagerly discussed. Therefore, in our second iteration of the theoretical base refinement, the value creation and business model angle was partly overlooked for further development and synthesis with the rest of the research lenses, as merely overlapping with adjacent concepts and management tools in practice-oriented shipping digitalization management.

In the following, in Table 2, we elaborate the main digitalization drivers that were validated or emerged through our case studies, as pertinent constructs of shipping digital strategy and business models.

\section{Digitalization management determinants and practices}

With our research framework, we also examine digitalization management practices, latently mirroring the seminal, evolving resource-based, and dynamic capabilities theories. Among a wealth of related frameworks, based on Bharadwaj (2000), we employed digital innovation capabilities as a practice oriented construct with six dimensions: digitalization strategic thinking, digital infrastructures (assets), digital business partnerships, and digital business process integration, structures and network orientation/connectivity. Hence, we examined digital innovation capabilities, as a compound construct, which reflects digitalization determinants (Ethiraj et al., 2005).

In addition, we examine the course of the various digital transformation activities and management practices along the different phases of the innovation process (sense-seizetransform digitalization loops), namely digital opportunity identification/ideation, digital initiative exploration and testing, and lastly, actual launching/operation of the digital technology systems/services (Salerno et al., 2015).

Also remarkably, in our field study, interviewees mostly did not directly discuss these questions, however, they did refer to management concepts and practices related with 
Table 2 Drivers of Shipping Digitalization vis-à-vis Digital Transformation Rational

\begin{tabular}{ll}
\hline Digitalization Drivers & Digital Transformation Logic \\
\hline Process improvements & Smart shipping systems automate via self-management properties the \\
planning, and actual operation of technical, commercial and support \\
functions of shipping. Main perceived advantages are further improvement \\
related with safety, and shippers and business partners' process \\
synchronization. Respective digital solutions are: condition-based ship \\
systems monitoring, self-adjustment of ship operations and real time \\
cargo monitoring. \\
Autonomous ship technologies and functions, such as autonomous \\
navigation, collision avoidance and berthing functions will further improve \\
safety and business performance. Complex or risk entailing activities can be \\
performed by autonomous vessels and automated ports infrastructures.
\end{tabular}

Cost Efficiency

Digitalization improves cost-efficiency in terms of a number of digital solutions: more accurate energy (fuel) consumption monitoring, emissions monitoring, crew cost optimization, digital twin platforms for integrated ship design and operation, predictive maintenance and safer ship operations with various levels of autonomy, also cargo monitoring.

Customer and Business Partners The traceability of freight throughout the shipping and maritime transport Expectations process, aligned with the whole supply chain and production processes is essential for the quality levels demanded by end customers. Shipping business is gradually aligning with this business model enabled by digitalization.

Data Monetization Models

New business models arise form datafication. Based on historical, real time, big and small data sets and advances in database, cloud and visualization technology but foremost computational techniques, maritime organizations may develop data platforms and data analytics based services and solutions to satisfy old and new strategic objectives and business models.

Radical Innovations

(i) Autonomous ships and (ii) blockchains are two radical innovations for the shipping industry. New knowledge, new market structures but also new sources of value are designed, tested and appropriated by competent actors. Incumbent, leading companies are involved in "edge exploration" in both these radical innovation fronts to secure an early mover position and control/ leverage related markets.

Market pressure

Competitors already use digital shipping technologies. It is imperative to secure a competitive advantage with digital technology and not lag behind the market standards.

Innovation Push

Innovative digital shipping systems create a dominant technology push force, and market competition, both enabling digital transformation. Shipping companies and maritime organizations recursively determine the particular models and practices to generate value.

Institutions

Industry associations, regulatory and standards organizations and related industry institutions play a role in setting norms, business and technical standards of digitalization, acting as exogenous factors.

what the literature essentially denotes as digital innovation capabilities, namely digital culture or digital leadership, partnerships and collaboration orientation, also learning/ market intelligence capability. This may be partly be ascribed to the fact that our interviewees were shipping business middle managers, not highly exposed to business school or academic business management nomenclature, also the digitalization projects they are involved and we studied are to a certain extent at the testing phase, not at the actual commercial or operational phase; hence, the success of the initiatives can not be effectively assessed, at this point, to a much lesser extent be correlated to particular management models and practices. Interviewees were mostly keen to discuss aspects related with the approach taken as regards the innovation process of digitalization systems development; therefore innovation process factors are also validated and maintained in the digitalization management theoretical framework as relevant. Last, we include the generic notions of opportunities and barriers of digitalization as appropriate 
prompts to address possibly missing aspects as regards the typology of technologies and digitalization management practices, in particular important barriers to digitalization.

In the following Table 3, the main digitalization management concepts, models and practices that were validated or emerged through our field research are outlined:

We concisely articulate the pertinent digitalization management antecedents, entailing innovation process, resource-based view and dynamic capabilities approaches and adjacent management theory and management practices, as follows:

A digital mindset is emergent, complementing traditional strategic-orientations of incumbent shipping companies. Shipping incumbents orchestrate their business activities along a combination of incremental and radical digital business models, where digital assets are the core strategic resource, together with conventional (analog) shipping business models. Strategic embeddedness and digital leadership are determinants of digitalization.

Digitalization management is an effort of balanced, portfolio strategy. The scope of digital transformation, the options for business model repurposing and "edge exploration" along with the prioritization logic of short-term improvements vs. paradigmatic digital technology projects and their strategy execution possibilities (i.e. partnerships, greenfield) entail different (often competing) business logics and innovation modes (exploration - exploitation).

A resourcing capability for vessels/fleets with autonomous functions embedded in IoT enabled cyber physical systems, innovative A.I. business software or blockchain applications is deliberately planned and materialized in various orders and rhythms. Technology-alliances and joint ventures are principal interorganizational collaboration forms, employed to address the uncertainties, knowledge dispersion and resource complementarities ingrained in digital transformation activities.

Business process management remains a demanding area; Implementing new digital solutions demands new, appropriate process integration solutions, mostly addressed today in terms of a pressing need for standardization (technology protocols and commercial software features).

Appropriate organization designs are implemented in the form of new departments (digital or smart shipping units), formalized cross departmental teams for digitalization projects development, also open innovation forms with external partners of complementary knowledge and business expertise. Internal also external collaboration is mostly the norm in digitalization processes.

Table 3 Shipping Digitalization Management

\begin{tabular}{ll}
\hline Concepts, Models, Practices & IS and Innovation Management Constructs \\
\hline Digital Innovation Capabilities & Digital Strategy First (Paradigm Shift and Digital Mindset) Resourcing \\
& (Autonomous Fleets, Smart Systems) \\
& Network and Platform orientation - Technology Partnerships \\
& Process Integration and Technology Standardization prioritization \\
& Organization Design (new business units, spin off structures, cross \\
& disciplinary teams) \\
& External and Internal Collaboration \\
& Sense-Seize-Transform Digitalization Loops, Agile Development, \\
Improvisation, Institutionalization & Explore vs. Exploit Innovation Mode (Balancing Digitalization Portfolios) \\
Innovation Process Practices & Collaborative-Open Innovation Model \\
\hline &
\end{tabular}


Digitalization as an innovation process entails the continuous scanning of the shipping markets and competitors, but foremost industry-spanning search for relevant business models and practices to adopt (i.e. autonomous vehicles). The ideation phase and project/system refinement in terms of iterative filtering, design, testing and validation up to commercialization and launching entail appropriate project management, design thinking and human resource management techniques and methodologies. Digitalization is different from previous technological innovation trajectories, with internal and external collaboration, and innovation platforms constituting best practice governance mechanisms. Henceforth, a digital transformation process as an organizational routine is supported by a mix of related methodologies (process heuristics), which serves as a digitalization improvisation and value capture mechanism. Those routines and mechanisms represent an institutionalized digital innovation process.

\section{Methodology and cases}

We studied five cases addressing heterogeneous instances of digitalization in the shipping industry. For each case, we performed in-depth interviews with key interviewees who were responsible for managing and implementing shipping and ship smart systems that engage IoT, big data and analytics, A.I. or blockchain technologies. An interview script with three sections, namely shipping digitalization strategy, digitalization technologies and systems in development or use, and effectual digitalization management approaches, guided the interviews. We typically started with a brief introduction of the study rationale and the request that the interviewees generally portray the shipping digitalization technologies that they consider important and how these are used and possibly shape new shipping strategies and business models, also how the digitalization is affecting shipping markets structure, shipping companies' and other stakeholders' management practices. In the following, the interviewees were asked to describe in detail how the particular key technologies of shipping digitalization enlisted are applied, used or offered by the interviewees' company; furthermore, to explain whether (and which) new functions, services are enabled by the digitalization projects or platforms they are involved, to explain to which extent current processes embed or leverage the functions, and to describe implications of the emergence of smart ship and smart shipping or blockchain technology with regards to their organizations' business processes and business models. In addition, the research protocol included the analysis of the innovation process and pertinent digital innovation capabilities enabled (or lack thereof) hindered their organization's digital transformation. Last, interviewees' were asked to comment and assess the overall potential, opportunities and challenges of shipping digitalization.

Due to the novelty of the shipping digitalization phenomenon, the companies/ organization/consortia we investigated were selected for two reasons: they are large, incumbent companies/organizations in the shipping industry, well renown for business and technological excellence and strategic orientation for quality and innovation. We ensured that the interviewees were engaged in shipping digitalization to an extent that merits an investigation. The selected groups of interviewees were expected to provide us with a comprehensive and representative view of shipping digitalization logics, factors and approaches, as they are experts in shipping management business, 
information technology, or marine engineering, and their responsibilities include managerial as well as a technical tasks. In specific, all interviews proceeded with cross-functional groups that involved experts from an array of information technology, operations, smart shipping, marketing departments/units or team members. We ensured that the interviewees' position, experience and complementary perspectives would allow us to investigate how shipping digitalization is shaped and is shaping the industry, and individual companies' and organization's management practices and strategies, as well as identify the technological trajectory of smart shipping services and autonomous ship systems.

Before conducting the interviews, we sent a two-page summary of the main interview questions (both in English and Japanese) to each organization or contact person, whereas each interview lasted for about an hour. Interviews were conducted in an open-ended and semi-structured manner. All interviews were conducted face-to-face, at the studied organizations' premises and were transcribed. Typically, interviews were conducted in Japanese and translated simultaneously in English.

More in detail, interviewees' groups, in all examined cases, consisted of three to five persons. Overall, 19 experts were interviewed for the presented digitalization cases, and were distributed as follows: Shipping Company A (3), Shipping Company B (5), Classification Society (5), Autonomous Vessel Consortium (3), Maritime Blockchain Consortium (3). In all cases, the interviewees groups included at least one and up to three C-level Executives, responsible for the respective digitalization project(s), being the head of respective departments/units (i.e. Smart Shipping Division, Marketing Division, ICT Strategy Department or Information System Department), or Project Managers of the respective initiatives (i.e. blockchain platform). In one case, the President of the respective Center and in two cases the Project Managers of the respective digitalization projects were interviewed and eagerly responded to the questions and open discussions. In all cases, we ensured that the position (organizational role) of the individual interviewees, also the mix of the interviewees' group members reflected the qualifications, experience and authority necessary to offer rich information and insight into shipping digitalization. Based on available literature and critiques of qualitative and case study research methods, in specific theory building from multiple cases, we considered the design, sampling and data collection and analysis process of our study as appropriate (Eisenhardt and Graebner, 2007; Goldkuhl 2019, Yin, 2014).

In addition, for triangulation purposes, secondary data was collected and analyzed, such as presentation slides, companies' presentation material, such as brochures and leaflets and additional material provided by interviewees after the meetings. This information helped us to frame the digital technologies and solutions' features and affordances discussed, also digitalization management logics and practices investigated.

Our research team consisted of two academics, and two postgraduate researchers, one of them being a senior civil servant, and expert in maritime transport matters.

In the following the findings of our research are summarized in Table 4. Shipping Companies A and B present a mostly converging portfolio of digitalization projects and initiatives, including smart applications for business and commercial, technical and nautical operations, and participation in one autonomous ship and two blockchain research projects and partnerships. 
The classification society organization is engaged in broad range of digitalization projects like software for ship inspections and shipping companies business consulting, also a radical innovation digitalization project, developing an open, data sharing platform for the shipping sector, also engaging shipping companies.

\section{Summary: theoretical contribution, managerial implications and limitations}

In our study, incumbent, leading shipping organizations with proven digitalization activities and experiences were examined in order to analyze organizational and management ramifications resultant from digital innovation. Employing a grounded theory methodological approach, we have developed a conceptual model with three intertwined pillars: digital technologies, digital solutions, and digitalization management best practices. We devised our theoretical model, it's constructs and perspectives, based on principal IS and Management literatures and contextualized and synthesized them so as to address and conceptualize the idiosyncrasies of shipping digitalization, today. Based on the field research findings, the extent of validation and the insights we gained with experts' interviews, our work contributes with an overarching model of digitalization, which presents pertinent technological and managerial aspects to be further developed, enhanced and validated by forthcoming maritime research studies.

Our research has certain limitations, mostly inherent in qualitative research; our multi-case study findings are not statistically representative.

Table 4 Study Findings

\begin{tabular}{|c|c|c|c|}
\hline $\begin{array}{l}\text { Case } \\
\text { Digitalization Technology } \\
\text { and } \\
\text { Solutions }\end{array}$ & $\begin{array}{l}\text { Digital Strategy } \\
\text { Drivers }\end{array}$ & $\begin{array}{l}\text { Digitalization Management } \\
\text { Determinants \& Practices }\end{array}$ & Challenges \\
\hline Shipping Company A & $\begin{array}{l}\text { Process } \\
\text { Improvements } \\
\text { Cost Reduction } \\
\text { Technology Push }\end{array}$ & $\begin{array}{l}\text { Strategic Thinking } \\
\text { Partnerships } \\
\text { Structures } \\
\text { (spin off technology company) } \\
\text { Explorative vs. Exploitative } \\
\text { Innovation Mode }\end{array}$ & $N / A$ \\
\hline Shipping Company B & $\begin{array}{l}\text { Competition } \\
\text { Process improvements } \\
\text { Cost Reduction } \\
\text { Customers' } \\
\text { Expectations }\end{array}$ & $\begin{array}{l}\text { Strategic Thinking } \\
\text { Partnerships } \\
\text { Structures (Smart shipping department) } \\
\text { Internal and External Collaboration } \\
\text { State of the Art Methodologies } \\
\text { Explorative vs. Exploitative Innovation } \\
\text { Mode }\end{array}$ & $\begin{array}{l}\text { Technology } \\
\text { Maturity } \\
\text { Cost Efficiency } \\
\text { Standards }\end{array}$ \\
\hline Classification Society & $\begin{array}{l}\text { Data Monetization } \\
\text { Radical Innovation }\end{array}$ & $\begin{array}{l}\text { Strategic Thinking -Paradigm Shift and } \\
\text { Digital Mindset } \\
\text { Open Data-Data Sharing Model } \\
\text { Network and Platform orientation } \\
\text { Internal and External Collaboration }\end{array}$ & $\begin{array}{l}\text { Market } \\
\text { Acceptance } \\
\text { Standards }\end{array}$ \\
\hline $\begin{array}{l}\text { Autonomous Vessel } \\
\text { Consortium }\end{array}$ & $\begin{array}{l}\text { Radical Innovation } \\
\text { Institutions } \\
\text { Technology Push }\end{array}$ & $\begin{array}{l}\text { Strategic Thinking -Paradigm Shift and } \\
\text { Digital Mindset } \\
\text { Internal and External Collaboration }\end{array}$ & $\begin{array}{l}\text { Cost-efficiency } \\
\text { Technology } \\
\text { Maturity } \\
\text { Standards }\end{array}$ \\
\hline $\begin{array}{l}\text { Maritime Blockchain } \\
\text { Consortium }\end{array}$ & $\begin{array}{l}\text { Radical Innovation } \\
\text { Institutions } \\
\text { Technology Push }\end{array}$ & $\begin{array}{l}\text { Strategic Thinking -Paradigm Shift and } \\
\text { Digital Mindset } \\
\text { Internal and External Collaboration }\end{array}$ & $\begin{array}{l}\text { Standardization } \\
\text { Market } \\
\text { Acceptance } \\
\text { Technology } \\
\text { Maturity }\end{array}$ \\
\hline
\end{tabular}


The nuances and heterogeneity of pertinent technologies, strategies, management practices as well as barriers, faced by shipping companies in different markets (i.e. bulk/container, liner/spot, Asian/European) needs further elaboration, since different factors and approaches are operand. Nonetheless, our sample organizations do operate or serve fleets in multiple markets, on a global scale; hence the evidence gained from our study can be assessed as representative and comprehensive of shipping digitalization.

Environmental (macro), institutional and cultural aspects, as influencing factors, are not considered either and should be also integrally addressed in future research, in order to understand why and how shipping companies engage in digitalization and perform differently, in various national, regional, sectoral and cultural settings.

Our paper addresses specific managerial implications of shipping digitalization. We present: (i) a concise model of three prevailing, intertwined dimensions to take into consideration while engaged in real life digitalization efforts; we elaborate in detail (ii) an accessible typology of pertinent technological components of shipping digitalization and (iii) a list of related managerial action fields to focus on while engaging in shipping digitalization projects. Hence, we provide one single accessible knowledge source for maritime professionals who wish to be updated in shipping digital technology and resultant managerial issues. Fostering the academic dialogue on shipping digitalization, also contributes in expanding maritime business professionals understanding of digitalization aspects and enriches their managerial agency quality.

\section{Concluding discussion: digital entrainment - old drivers, appropriated practices, new value?}

In conclusion, we contribute with the conceptualization of a baseline, practice oriented model of shipping digitalization, still we seek to identify and test significant antecedents and determinants, beyond what is currently perceived as relevant. We pursue identifying rational business heuristics for entrepreneurial action, shaping and being shaped by an emergent "digital habitus" (Bourdieu, P. 1990; Abdelnour et al. 2017).

Possible future research directions for theorizing the shipping digitalization phenomenon, are outlined in the following:

A. Cross-connecting firm characteristics (size, experiences, alliances-network position, strategic orientations) and intra-organization characteristics (stakeholders, governance and incentives, management cognitive factors and agency, structures and innovation processes) with macro-perspectives, in particular ecosystem and institutional dimensions merits further examination (Eggers and Park, 2018).

B. Detecting interdependencies of those derived, fine-grained antecedents of shipping digitalization, taking the form of causal relationships (i.e. firm identity and digital strategy misalignment) are points of research action that can be pursued in forthcoming studies.

C. The nature (phases, rhythms) of the digital transformation trajectory, i.e. accruing selectively digitalization projects, systems and activities, employing and partnering with those with relevant resources, interests, and predispositions, also balancing opposing value creation logics, accounts to a prototypical shipping digitalization s-curve and needs to be further elaborated.

Furthermore, the following observations could be investigated: 
(i) As a resource-based perspective dictates and our study insights indicate, shipping companies explore new configurations of analog shipping resources in combination with digital resources to create digital transformation outcomes (value). The intensity and direction in which resources are explored and combined are correlated with digitalization performance and needs further examination.

(ii) Our insights suggest that innovation process practices, including industryspanning search, complex system thinking style (sensing capability) and orchestration (seizing) capabilities are correlated with digitalization performance, also linked to the radicalness of digital innovation (i.e. business model innovation such as blockchain platforms and autonomous ships projects vs. process innovations).

(iii) Digital value creation logics and processes apparently overlap and are interwoven and need to be further scrutinized.

(iv) Managing digitalization is more complicated than acquiring, bundling and orchestrating physical and digital resources. The relationship between analog shipping and digital technology efforts can be examined further (Cohen and Tripsas, 2019). Our insights suggest that a value creation logic that maintains a relatively stable focus on balancing analog and digital shipping is a predictor of digitalization performance. In addition, using competently analog shipping knowledge to bridge traditional and digital generations of shipping can have a positive impact on digitalization performance.

(v) Likewise, our insights suggest that resource complementarity is the primary driver for which shipping companies pursue interorganizational collaboration; it constitutes a process with potential partners reciprocally strategizing through interactions and mingled actions. Relationship making, integration and orchestration capabilities for resource complementarity have an impact on digitalization performance.

Along the above line of reasoning, the nuances of shipping digitalization value creation logics, resourcing practices, innovation capabilities and organization designs need to be further scrutinized.

Beyond, a rationalistic, positivist analysis, competent adaptive actions incurred to shipping digitalization management can be perceived as "digital habitus-driven" (Nayak, et al. 2019), where practitioners sense the affordances of digital technologies and solutions, through the shipping company's organizational culture, a refined sensitivity to affordances, and a "nurtured predisposition to capitalize on such affordances in situ" (Nayak, et al. 2019). Further combined with business heuristics are extended to effect "entrepreneurial action", where practitioners seize digitalization opportunities and direct their companies' strengths so as to transform their customary business logic toward development, sustainability and progress.

\section{Acknowledgements}

Not applicable.

\section{Authors' contributions}

ML contributed with the problem identification, literature review and theory development, also conducting the interviews and interpreting the data collected regarding digitalization in shipping (technologies, solutions, practices). DW also contributed with literature review, theory development, contacting the organizations which were investigated for the field research (interviews), organizing also conducting the interviews and interpreting the data collected regarding digitalization in shipping (technologies, solutions, practices). Jl also contributed with theory development, organizing and conducting the interviews and interpreting the data collected regarding digitalization in shipping. ML had the primary role in writing the manuscript. All authors read and approved the final manuscript. 


\section{Availability of data and materials}

The datasets used and analysed during the current study are available from the corresponding author on reasonable request.

\section{Competing interests}

Not applicable.

\section{Author details}

${ }^{1}$ University of the Aegean, Department of Shipping, Trade and Transport, Chios, Greece. ${ }^{2}$ Tokyo University of Marine Science and Technology, Department of Logistics and Information Engineering, Tokyo, Japan. ${ }^{3}$ Ministry of Land Infrastructure, Transport and Tourism, National Institute for Land and Infrastructure Management, International Coordination Division, Yokosuka, Kanagawa, Japan.

Received: 20 August 2019 Accepted: 31 October 2019

Published online: 21 November 2019

\section{References}

Abdelnour S, Hasselbladh H, Kallinikos J (2017) Agency and institutions in organization studies. Organ Stud 3812:1775-1792

Andal-Ancion A, Cartwright P, Yipet G (2012) The digital transformation of traditional business. MIT Sloan Manage Rev 44(4):34-41

Atzori L, lera A, Morabito G (2010) The internet of things: a survey. Comput Netw 54(15):2787-2805

Barney J (1991) Firm resources and sustained competitive advantage. J Manage 17(1):99-120

Barrett M, Davidson E, Prabhu J, Vargo SL (2015) Service innovation in the digital age: key contributions and future directions. MIS Quart 39(1):135-154

Beck R, Avital M, Rossi M et al (2017) Blockchain Technology in Business and Information Systems Research, business and information systems engineering. Bus Inf Syst Eng 59(6):381-384

Bharadwaj A, El Sawy OA, Pavlou PA, Venkatraman N (2013) Digital business strategy: toward a next generation of insights. MIS Quart 2(37):471-482

Bharadwaj AS (2000) A resource-based perspective on information technology capability and firm performance: an empirical investigation. MIS Quart 24(1):169-196

Bordeleau F E, Musconi E, De Santa-Eulalia LA (2018) Business Intelligence in Industry 4.0: State of the art and research opportunities. In: Proceedings of HICSS 2018, Hawaii, January 3-6, 2018

Bourdieu P (1990) The logic of practice. Polity Press, Cambridge

Chesbrough H (2010) Business model innovation: opportunities and barriers. Long Range Plan 43(2):354-363

Cohen SL, Tripsas M (2019) Managing technological transitions by building bridges. Acad Manag J 61(6):2319-2342

Colbert A, Yee N, George G (2016) The digital workforce and the workplace of the future. Acad Manag J 59(3):731-773

Demirkan H, Bess C, Spohrer J, Rayes A, Allen D, and Moghaddam Y (2015) Innovations with smart service systems: analytics, big data, cognitive assistance, and the internet of everything. Commun AIS 37.1, article 35

Eggers JP, Park KF (2018) Incumbent adaptation to technological change: the past, present, and future of research on heterogeneous incumbent response. Acad Manag Ann 12(1):357-389

Eisenhardt KM, Graebner ME (2007) Theory building from cases: opportunities and challenges. The Acad Manage J 50(1):25-32

Eisenhardt KM, Martin JA (2000) Dynamic capabilities: what are they? Strateg Manage J 21(10):1105-1121

El Noshokaty S (2017) Shipping optimisation systems (SOS): tramp optimisation perspective. Journal of Shipping and Trade 2(3):1-36.

Ethiraj SK, Kale P, Krishnan MS, Singh JV (2005) Where do capabilities come from and how do they matter? A study in the software services industry. Strateg Manage J 26(1):25-45

Fitzgerald M et al (2014) Embracing digital technology: a new strategic imperative. MIT Sloan Manage Rev 55(2):1

Goldkuhl G (2019) The generation of qualitative data in information systems research: the diversity of empirical research methods. Communications of the AIS 44:572-599

Henfridsson O, Bygstad B (2013) The generative mechanisms of digital infrastructure evolution. MIS Quart 37(3):907-931

Jokioinen E (2017) Remote and autonomous ship - the next steps. AAWA Project Position Paper http://docplayer.net/19502 019-Remote-and-autonomous-ships-the-next-steps.html

Kane G, Kiron D, Palmer D, Buckley N, Philips AN (2015) Strategy, not technology, Drives Digital Transformation: Becoming a digitally mature enterprise. MIT Sloan Manage Rev https://sloanreview.mit.edu/projects/strategy-drives-digitaltransformation/

Legner C, Eymann T, Hess T, Matt C, Böhmann T, Drews P, Mädche A, Urbach N, Ahlemann F (2017) Digitalization: opportunity and challenge for the business and information systems engineering community. Bus Inf Syst Eng 59(4):301-308

Levander O (2017) Forget autonomous cars-autonomous ships are almost here. IEEE Spectr 54(2):26-31

Liere-Netheler K, Packmohr S, Vogelsang K (2018) Drivers of digital transformation in manufacturing, in: proceedings of HICSS 2018, Hawaii, January 3-6, 2018

Loebbecke C, Picot A (2015) Reflections on societal and business model transformation arising from digitization and big data analytics: a research agenda. J Strateg Inf Syst 24(3):149-157

Lycett M (2013) Datafication: making sense of (big) data in a complex world. Eur J Inform Syst 22(4):381-386

McAfee A, Brynjolfsson E (2012) Big data: the management revolution. Harvard Bus Rev 90:61-67

Mlimbila J, Mbamba UOL (2018) The role of information systems usage in enhancing port logistics performance: evidence from the Dar Es Salaam port, Tanzania. J Shipping Trade 3(1):1-20

Nambisan S, Lyytinen K, Majchrzak A, Song M (2017) Digital innovation management: reinventing innovation management research in a digital world. MIS Quart 41(1):223-238 
Nayak A, Chia R, Canales JI (2019) Non-cognitive microfoundations: understanding dynamic capabilities as idiosyncratically refined sensitivities and predispositions. Acad Manag Rev. https://doi.org/10.5465/amr.2016.0253

Nylén D, and Holmström J (2015) Digital innovation strategy: a framework for diagnosing and improving digital product and service innovation, Bus Horizons. 58. 1, 57-67

Osterwalder A, Pigneur Y, Tucci CL (2005) Clarifying business models: origins, present and future of the concept. Communications of the AIS 15:1-43

Pfohl HC, Yahsi B, Kurnaz T (2015) The impact of industry 4.0 on the supply chain. In: proceedings of the Hamburg international conference of logistics HICL 2015, Hamburg, august 2015

Pilkington M (2016) Blockchain technology: principles and applications. Research handbook on digital transformations. (eds) F. Xavier Olleros and Majlinda Zhegu. Edward Elgar

Saldana J (2009) The coding manual for qualitative researchers. Sage, London

Salerno M, Gomes L, Silva D, Bagno R, Freitas S (2015) Innovation processes: which process for which project. Technovation 35:59-70

Shmueli G, Koppius OR (2011) Predictive analytics in information systems in research. Manag Inf Syst Q 35(3):553-572

Sternberg H, Baruffaldi G (2018) Chains in Chains - Logic and Challenges of Blockchains in Supply Chains. In: Proceedings of HICSS 2018, Hawaii, January 3-6, 2018

Svahn F, Mathiassen L, Lindgren R (2017) Embracing digital innovation in incumbent firms: how Volvo cars managed competing concerns. MIS Quart 41(1):239-253

Szimba E, Ihrig J, Kraft M, Mitusch K, Chen M, Chahim M, Meijeren J, Kiel J, Mandel B, Ulied A, Larrea E, Ceuster G, Grol R, Berki Z, Székely A, Smith R (2018) HIGH-TOOL - a strategic assessment tool for evaluating EU transport policies. J Shipping Trade 3(11):1-30

Teece DJ (2010) Business models, business strategy and innovation. Long Range Plan 43(2):172-194

Teece DJ, Pisano G, Shuen A (1997) Dynamic capabilities and strategic management. Strateg Manage J 18(7):509-533

Thomas LD, Autio E, Gann DM (2014) Architectural leverage: putting platforms in context. Acad Manage Perspect 28(2):198-219

Underwood S (2016) Blockchain beyond Bitcoin. Commun ACM 59(11):15-17

Wiesböck F (2018) Thinking outside of the IT capability box in: proceedings of the 24th Americas conference on information systems (AMCIS 2018). New Orleans USA, August 16-18:2018

Yin RK (2014) Case study research: design and methods. Sage, Los Angeles, CA

Yoo Y, Henfridsson O, Lyytinen K (2010) Research commentary-the new organizing logic of digital innovation: an agenda for information systems research. Inform Syst Res 21(4):724-735

Zott C, Amit R, Massa L (2011) The business model: recent developments and future research. J Manage 37:1019-1042

\section{Publisher's Note}

Springer Nature remains neutral with regard to jurisdictional claims in published maps and institutional affiliations.

\section{Submit your manuscript to a SpringerOpen ${ }^{\circ}$ journal and benefit from:}

- Convenient online submission

- Rigorous peer review

- Open access: articles freely available online

- High visibility within the field

- Retaining the copyright to your article

Submit your next manuscript at $\boldsymbol{s p r i n g e r o p e n . c o m ~}$ 